\title{
GENDER, EXCESSIVE BODY WEIGHT, AND PSYCHOLOGICAL WELL-BEING IN ADULTHOOD
}

\author{
Jamila Bookwala and Jenny Boyar \\ Lafayette College
}

\begin{abstract}
We examined gender differences in the association between body mass index (BMI) and psychological well-being. Regression analysis involving 3,251 adults indicated that gender moderated the BMI-psychological well-being link. In follow-up analyses, higher BMI predicted lower psychological well-being only among women. When participants were categorized into 5 BMI groups, women reported lower psychological well-being than men in the overweight and obese I groups, but no gender differences were observed in the more seriously obese or normal-weight groups. Also, among women, all 4 groups with higher-than-normal BMI had lower psychological well-being than normal-weight women; for men, no significant differences were found across the 5 groups. These findings are discussed in relation to research on stigma theory and gender-differentiated cultural norms regarding weight.
\end{abstract}

Excessive body weight in adulthood has emerged as one of the most serious health concerns in the nation today $(\mathrm{Na}-$ tional Center for Health Statistics [NCHS], 2006; National Heart, Lung, and Blood Institute [NHLBI], 1998; Ogden, Carroll, Curtin, McDowell, \& Tabak, 2006). Using body mass index (BMI) as the marker, the most recent estimates indicate that $66 \%$ (or 133.6 million) of the U.S. adult population is characterized by excessive weight $(\mathrm{BMI} \geq 25)$, with $32.1 \%$ considered obese (BMI $\geq 30$; NCHS, 2006). These prevalence estimates vary across adult women and men. A larger proportion of men are overweight or of higher weight than are women $(70.7 \%$ vs. $61.4 \%$, respectively), but when considering only obesity, more women are obese than are men (34\% vs. $30.2 \%$, respectively; NCHS, 2006). Excessive body weight and obesity have been linked to a significantly greater incidence of a host of chronic diseases, including Type 2 diabetes, cardiovascular disease, hypertension and stroke, and certain forms of cancer (NHLBI, 1998; World Health Organization, 2002). Recent evidence also indicates that being either overweight or obese is associated with an increased mortality risk (Adams et al., 2006).

In contrast with the strong link between being overweight or obese and having poorer physical health, the link between excessive body weight and psychological wellbeing is less clear-cut, with empirical studies showing

Jamila Bookwala and Jenny Boyar, Department of Psychology, Lafayette College.

Address correspondence and reprint requests to: Jamila Bookwala, Department of Psychology, 305 Oechsle Hall, Lafayette College, Easton, PA 18042. E-mail: bookwalj@lafayette.edu inconsistent relationships between body weight and poor mental health (Friedman \& Brownell, 1995; NHLBI, 1998). Early studies found little or no association between obesity and negative psychological outcomes (see Friedman \& Brownell, 1995; O’Neill \& Jarrell, 1992; Wadden \& Stunkard, 1993). More recent studies, however, have reported an association between excessive body weight and poorer psychological well-being. For example, on studying the relationship between obesity and psychological distress in a population of treatment-seeking obese individuals, Friedman and associates (Friedman, Reichmann, Constanzo, \& Musante, 2002; Friedman et al., 2005) found that higher BMI was associated with greater negative affect and lower self-esteem. When Wang and colleagues (2006) examined prevalence rates of excessive body weight/obesity in a sample of adult women and men with bipolar disorder, they found that $31 \%$ of women and $21 \%$ of men with bipolar disorder were obese.

Recent studies also have found a negative relationship between excessive BMI and psychological health using samples that have been drawn with probability-sampling techniques. For example, Carr and her colleagues found lower self-acceptance (Carr \& Friedman, 2005) and higher negative affect (Carr, Friedman, \& Jaffe, 2007) in very obese adults (BMI $\geq 35$ ). In an epidemiologic survey of over 9,000 adults in the United States, Simon and his colleagues (2006) found that obese individuals had a higher risk (21-47\%) of lifetime prevalence of mood and anxiety disorders compared to those with a BMI of $\leq 30$ (i.e., nonobese individuals). In a large sample, Heo, Pietrobelli, Fontaine, Sirey, and Faith (2006) found that both overweight and obese young women and overweight young men were significantly more 
likely to have experienced a depressed mood than their normal-weight counterparts.

Based on theoretical and empirical developments in the field of stigma research, we can expect that overweight and obese individuals will experience poorer psychological well-being than their normal-weight counterparts. Individuals characterized by excessive weight are commonly stigmatized by society (Allon, 1981; Friedman et al., 2005; Sarlio-Lahteenkorva, Stunkard, \& Rissanen, 1995). Studies show that obese individuals often experience a decline in social status and report experiencing prejudice and discrimination (Carr \& Friedman, 2005; Crandall, 1994; Faulkner et al., 1999; Mustajoki, 1987). Obese individuals' excessive weight is related to perceptions by others as being physically unattractive (Puhl \& Brownell, 2001). Negative attributes such as laziness, lack of self-discipline, self-indulgence, and unhappiness also are often ascribed to obese individuals (Crandall \& Schiffhauer, 1998; Harris, Harris, \& Bochner, 1982; Tiggemann \& Rothblum, 1998).

Unlike some other groups that experience social stigma (e.g., individuals with disabilities, members of racial and religious minorities), individuals with excessive body weight tend to be viewed as responsible for their stigmatized condition (Allon, 1981; Weiner, Perry, \& Magnusson, 1988). Indeed, obese individuals often hold prejudices within their own group (Crandall, 1994; Crocker, Cornwell, \& Major, 1993; Latner, Stunkard, \& Wilson, 2005). For example, Crocker, Cornwell, and Major (1993) found that when overweight women experienced discrimination from a White male, they were more likely to view the male's attitude as justified, blaming themselves rather than the discriminating male. Their stigmatized status also appears to have an impact on overweight and obese individuals' social interactions. In their study of normal-weight, overweight, and obese participants, Carr and Friedman (2006) found that overweight and obese individuals reported greater social strain and less support in familial relationships.

Research indicates that stigmatizing experiences related to being overweight or obese can vary by gender. For example, Neumark-Sztainer et al. (2002) examined the experience of teasing in a population of adolescents. They found that overweight girls reported that they were especially bothered by others' teasing. Faulkner et al. (1999) found that, compared to men, women were significantly more likely to experience perceived mistreatment due to weight from a stranger. Likewise, in a series of focus groups, Cossrow, Jeffery, and McGuire (2001) found that women participants reported a greater number and variety of negative experiences related to their excessive weight, compared to men. These experiences encompassed teasing, slurs and insults, harassment, negative judgments and assumptions, and perceived discrimination related to their weight. Chen and Brown (2005) found that, relative to obese men, obese women were more likely to experience stigmatization by men during a sexual-partner choice task.
We hypothesize that, in light of the gender differences observed in the experience of stigma and discrimination related to excess weight (Cossrow et al., 2001; Faulkner et al., 1999; Neumark-Sztainer et al., 2002), gender will moderate the relationship between BMI and psychological well-being. It is important to examine this issue because poorer psychological well-being, in turn, may make women of excessive weight more vulnerable than men to serious psychological problems such as mood or anxiety disorders (Wang et al., 2006). We specifically hypothesize that excessive weight (i.e., higher BMI) will be more strongly related to poorer psychological well-being for women than for men. Moreover, because past research indicates that overweight and obese individuals are particularly susceptible to holding a negative body image and experiencing greater body dissatisfaction (Brodie \& Slade, 1988; Sarwer, Wadden, \& Foster, 1998; Sinclair \& Myers, 2004; Stunkard $\&$ Mendelson, 1967; Weaver \& Byers, 2006) and, in turn, that a reliable relationship exists between body image and psychological well-being (e.g., Davison \& McCabe, 2005; McKinley \& Hyde, 1996; Weaver \& Byers, 2006), we considered it important to parse the effects of excessive body weight on psychological well-being from those of body image (or perceived weight). Thus, we retested our hypothesis by adding participants' perceived weight to the model. Finally, because higher-than-normal BMI varies by sociodemographic characteristics (NCHS, 2006; NHLBI, 1998), we also retest the moderating role of gender in the BMIpsychological well-being association with these variables added to the model, following the approach adopted by Carr and Friedman (2005).

\section{METHOD}

\section{Sample}

The sample for this study was drawn from the main sample of adults who participated in the National Survey of Midlife Development in the United States I (MIDUS I; Brim et al., 2003). MIDUS I was designed to assess a wide variety of patterns, predictors, and outcomes related to physical health, psychological well-being, and social responsibility during the adult years. It assessed these variables in 1995 and 1996 in a nationally representative sample of 4,242 individuals between the ages of 25 and 74 years using telephone (phase 1) and follow-up mail (phase 2) questionnaires. The main sample of MIDUS I had a response rate of $70 \%$ for the telephone interview, with nearly $87 \%$ of those interviewed over the telephone completing the mailed portion of the survey; this yielded an overall response rate of approximately $61 \%$. The present study sample $(N=3,251)$ included those MIDUS I respondents who completed both the telephone and mail questionnaires, had a normal or higher BMI $(\mathrm{BMI} \geq 18.5),{ }^{1}$ and had complete data on all study variables. On average, the sample was 47.3 years of age (range $=25$ $74 ; S D=13.2) ; 48.8 \%(n=1,588)$ of the respondents were 
women; $88.3 \%(n=2,870)$ described themselves as White; $63.1 \%(n=2,050)$ had at least some college education; and approximately $64 \%(n=2,090)$ were married.

\section{Measures}

Respondents' gender, age, race, education, and marital status were assessed during the telephone interview using standard assessments; for the data analyses, we dichotomized race (White vs. Other) and marital status (not married vs. married). Participants' height and weight, perceived weight, and psychological well-being were measured as part of the mail survey.

Body Mass Index (BMI). We treated BMI as a continuous variable in the regression models. MIDUS I participants provided data on their weight (in pounds) and height (in inches). To compute BMI, respondents' weight was first converted into kilograms (weight in pounds $x$ 0.4536 ) and their height was converted into meters (height in inches $\times 0.0254$ ). Next, BMI was calculated by taking respondents' weight in kilograms and dividing by height in meters squared.

Psychological well-being. Ryffs (1989) assessment of psychological well-being was included in MIDUS I. A total of 18 items were included, three measuring each domain represented in the Ryff measure: positive relations with others (e.g." "maintaining close relationships has been difficult and frustrating for me"), self-acceptance (e.g., "I like most parts of my personality"), autonomy (e.g., "I tend to be influenced by people with strong opinions"), personal growth (e.g., "For me, life has been a continual process of learning, changing, and growth"), environmental mastery (e.g., "The demands of everyday life often get me down"), and purpose in life (e.g., "Some people wander aimlessly through life, but I am not one of them"). Because new research has found that these six domains load on a single underlying fac- tor (see Springer, Hauser, \& Freese, 2006), we combined scores on these 18 items to form a single composite measure of psychological well-being. Item responses were made on a 7-point scale ranging from 1 (strongly agree) to 7 (strongly disagree). Items were reverse coded as needed and scores were summed so that higher scores represented greater levels of psychological well-being. We obtained a Cronbach's alpha value of .81 for this 18-item measure of psychological well-being.

Perceived weight. The MIDUS I included a single-item measure of respondents' perceived weight. Respondents were asked to describe themselves on a 5-point scale ranging from very underweight (5) to about the right weight (3) to very overweight (1). Scores were first reversed on this measure and, when correlated with BMI, we obtained a strong positive correlation $(r=.66)$, with higher BMI related to the perception of being overweight.

\section{RESULTS}

Descriptive statistics on sociodemographic characteristics, BMI, psychological well-being, and perceived weight are provided separately for women and men in Table 1. Women and men did not differ significantly on age, $t(3249)=-.96$, $p=.336$, or ethnicity, $\chi^{2}(1, N=3,251)=3.81, p=.051$, but fewer women, compared to men, had some college education or better, $\chi^{2}(3, N=3,251)=44.40, p<.001$, and more men were married compared to women, $\chi^{2}(1, N=$ $3,251)=67.13, p<.001$. Women had a significantly lower BMI relative to men, $t(3249)=2.59, p=.01$, but were more likely to perceive themselves to be overweight compared to men, $t(3249)=10.45, p<.001$. Women also reported lower psychological well-being than men, $t(3249)=2.70, p<.01$.

To examine the extent to which gender moderated the association between BMI and psychological well-being, we first regressed psychological well-being on respondents'

Table 1

Descriptive Statistics for Women and Men

\begin{tabular}{|c|c|c|c|c|c|c|}
\hline & \multicolumn{3}{|c|}{ Women $^{a}$} & \multicolumn{3}{|c|}{$\operatorname{Men}^{b}$} \\
\hline & $\%$ & $M$ & $(S D)$ & $\%$ & $M$ & $(S D)$ \\
\hline Age & & 47.5 & $(13.2)$ & & 47.1 & $(13.2)$ \\
\hline Education $(\% \text { some college or higher })^{c}$ & $60.3 \%$ & & & $65.6 \%$ & & \\
\hline Ethnicity (\% caucasian) & $87.2 \%$ & & & $89.4 \%$ & & \\
\hline Marital status $(\% \text { married })^{\mathrm{c}}$ & $57.2 \%$ & & & $71.0 \%$ & & \\
\hline $\mathrm{BMI}^{\mathrm{b}}$ & & 26.7 & (6.1) & & 27.1 & $(4.3)$ \\
\hline Psychological well-being ${ }^{\mathrm{d}}$ & & 98.8 & $(14.6)$ & & 100.1 & $(14.0)$ \\
\hline Perceived weight ${ }^{\mathrm{d}}$ & & 3.9 & $(0.7)$ & & 3.6 & $(0.7)$ \\
\hline
\end{tabular}

Note. Higher scores represent higher body mass index (BMI), psychological well-being, and perceived weight.

a $(n=1,588)$.

$\mathrm{b}(n=1,663)$.

${ }^{\mathrm{c}} \chi^{2}$ test of association significant at $p \leq .01$.

${ }^{\mathrm{d}}$ Mean difference between women and men significant at $p \leq .01$. 
Table 2

Regression Analyses for Three Models Predicting Psychological Well-Being $(N=3,251)$

\begin{tabular}{|c|c|c|c|c|c|c|c|c|c|c|c|c|}
\hline & \multicolumn{3}{|c|}{ Step 1} & \multicolumn{3}{|c|}{ Step 2} & \multicolumn{3}{|c|}{ Step 3} & \multicolumn{3}{|c|}{ Step 4} \\
\hline & $B$ & $S E B$ & $\beta$ & $B$ & $S E B$ & $\beta$ & $B$ & $S E B$ & $\beta$ & $B$ & SE B & $\beta$ \\
\hline Model 1 & \multicolumn{3}{|c|}{$R^{2}=.013$} & \multicolumn{3}{|c|}{$\Delta R^{2}=.004$} & & & & & & \\
\hline Gender $^{\mathrm{a}}$ & -1.47 & .50 & $-.05^{* *}$ & -1.44 & .50 & $-.05^{* *}$ & & & & & & \\
\hline BMI & -.24 & .05 & $-.09^{* * *}$ & -.01 & .08 & -.00 & & & & & & \\
\hline Gender $\times$ BMI & & & & -.34 & .10 & $-.10^{* *}$ & & & & & & \\
\hline Model 2 & & & & & & & \multicolumn{3}{|c|}{$\Delta R^{2}=.00$} & & & \\
\hline Gender & & & & & & & -1.53 & .52 & $-.05^{* *}$ & & & \\
\hline BMI & & & & & & & -.04 & .10 & -.01 & & & \\
\hline Gender $\times$ BMI & & & & & & & -.34 & .10 & $-.10^{* * *}$ & & & \\
\hline Perceived weight & & & & & & & .26 & .47 & .01 & & & \\
\hline Model 3 & & & & & & & & & & & $\Delta R^{2}=$ & \\
\hline Gender & & & & & & & & & & -.24 & .52 & -.01 \\
\hline BMI & & & & & & & & & & .06 & .10 & .02 \\
\hline Gender $\times$ BMI & & & & & & & & & & -.31 & .10 & $-.09^{* *}$ \\
\hline Perceived weight & & & & & & & & & & -.57 & .47 & -.03 \\
\hline Age & & & & & & & & & & .04 & .02 & $.04^{*}$ \\
\hline Ethnicity ${ }^{\mathrm{b}}$ & & & & & & & & & & 1.19 & .77 & .03 \\
\hline Education & & & & & & & & & & 3.00 & .26 & $.20^{* * *}$ \\
\hline Marital status ${ }^{\mathrm{c}}$ & & & & & & & & & & 4.00 & .52 & $.13^{* * *}$ \\
\hline
\end{tabular}

Note. Higher scores on continuous variables represent higher psychological well-being, higher body mass index (BMI), perceiving oneself to be of greater weight, being older, and being more educated. Regression coefficients obtained for each step of the three regression models are presented; regression coefficients obtained for steps 1 and 2 in Models 2 and 3 were the same as in Model 1 and for step 3 in Model 3 were the same as in Model 2.

${ }^{\mathrm{a}} 1=$ female, $0=$ male.

${ }^{\mathrm{b}} 1=$ Caucasian, $2=$ other.

${ }^{\mathrm{c}} 2=$ married, $1=$ other.

${ }^{*} p<.05 .{ }^{* *} p<.01 .{ }^{* * *} p \leq .001$.

BMI and gender on step 1 and the interaction of gender and BMI on step 2. The results of this regression analysis are presented in Table 2 (see Model 1). For this analysis, BMI scores were centered around the mean and the interaction term was created using the centered BMI scores and dummy-coded gender. A significant interaction term on step 2 in this model indicates that the relationship between BMI and psychological well-being is significantly different for women and men.

The data in Model 1 of Table 2 shows that being female and having a higher BMI were significantly associated with lower psychological well-being in the regression model, $F(2$, $3,248)=15.78, p<.001$. In addition, the gender and BMI interaction term was statistically significant on step 2 , indicating that gender moderated the BMI-psychological wellbeing link, $\Delta F(2,3,247)=11.91, p=.001$. We performed a second regression analysis (see Model 2 in Table 1), in which we introduced perceived weight as a covariate in step 3. Perceived weight was not significantly associated with psychological well-being after controlling for respondents' gender, BMI, and their interaction, $\Delta F(1,3,246)=$ $.30, p=.582$. Finally, consistent with the approach used by Carr and Friedman (2005), we added the sociodemographic variables of age, education, ethnicity, and marital status in step 4 (see Model 3, Table 2). These variables collectively improved the regression model, $\Delta F(4,3,242)=48.66$, $p<.001$; being older, more educated, and married were sig- nificantly related to higher psychological well-being. More importantly, however, the significant gender and BMI interaction effect obtained in Model 1 remained significant in both Models 2 and 3. Next, follow-up regression analyses were performed separately for women and men to determine the nature of the moderating effect of gender obtained in Model 1. These analyses indicated that BMI was a significant predictor of psychological well-being for women, $F(1$, $1,586)=35.26, p<.001, R^{2}=.022$, but was not associated with psychological well-being among men, $F(1,1,661)=$ $.014, p=.906, R^{2}=.00$.

To further parse the gender and BMI interaction for psychological well-being, we used guidelines provided by the NHLBI (1998) to categorize participants into different body weight groups. Participants with higher-than-normal BMI were placed into one of four groups: overweight $(25 \leq$ BMI $<30)$, obese I $(30 \leq$ BMI < 35), obese II $(35 \leq$ BMI $<40)$, and obese III $(\mathrm{BMI} \geq 40)$. Participants with a BMI in the normal (healthy) range $(18.5 \leq \mathrm{BMI}<$ $25)$ were categorized as normal weight. Then we compared women and men in those five weight groups on psychological well-being (see Figure 1). First, using a series of $t$ tests, we compared women and men on psychological wellbeing separately for each BMI group. As indicated in Table 3, women and men in the normal-weight group did not differ significantly on psychological well-being, but in the overweight and obese I groups, women scored significantly 
Table 3

Mean Comparisons on Psychological Well-being by Gender and Body Weight Groups

\begin{tabular}{|c|c|c|c|c|c|c|c|c|c|c|c|}
\hline & \multicolumn{4}{|c|}{ Women $^{a}$} & \multicolumn{4}{|c|}{$\mathrm{Men}^{b}$} & \multirow[b]{2}{*}{$t$} & \multirow[b]{2}{*}{$p$} & \multirow[b]{2}{*}{$\eta^{2}$} \\
\hline & $n$ & $M$ & $S D$ & SE & $n$ & $M$ & $S D$ & $S E$ & & & \\
\hline Normal-weight & 766 & 100.7 & 14.2 & .51 & 544 & 99.9 & 14.7 & .63 & -.93 & .355 & .001 \\
\hline Overweight & 449 & 98.3 & 14.2 & .67 & 786 & 100.4 & 13.4 & .48 & 2.67 & .009 & .006 \\
\hline Obese I & 221 & 96.2 & 15.5 & 1.0 & 252 & 100.4 & 13.6 & .86 & 3.15 & .002 & .021 \\
\hline Obese II & 96 & 95.1 & 14.8 & 1.5 & 54 & 98.6 & 16.1 & 2.2 & 1.36 & .176 & .012 \\
\hline Obese III & 56 & 92.6 & 14.3 & 1.9 & 27 & 95.5 & 18.9 & 3.6 & .79 & .432 & .008 \\
\hline
\end{tabular}

Note. $F$ statistics correspond with comparisons across body weight groups within each gender; $t$ statistics correspond with comparisons across gender within each body weight group.

${ }^{\mathrm{a}} F(4,1583)=9.49, p<.001, \eta^{2}=.023$

${ }^{b} F(4,1658)=.99, p=.412, \eta^{2}=.002$.

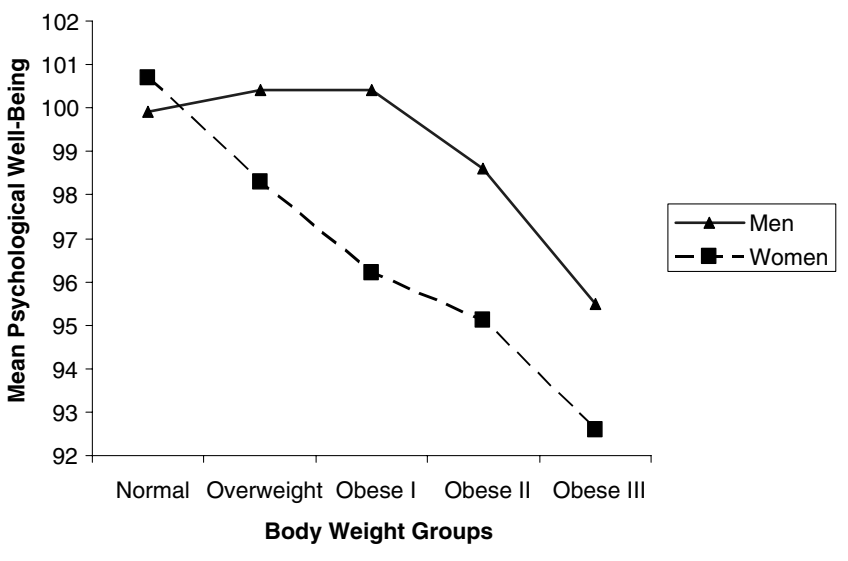

Fig. 1. Mean differences in psychological well-being of men and women by body weight group.

lower than men on psychological well-being. In the more seriously obese groups, however, the mean differences on psychological well-being between women and men were not statistically significant. Next, we performed analysis of variance tests separately for women and men to compare the five BMI groups on psychological well-being. We found that among women all four groups with higher-than-normal BMI had significantly lower psychological well-being than normal-weight women. Further, women in the obese III group had significantly lower psychological well-being than overweight women. Among men, however, the five BMI groups did not differ significantly from one another on psychological well-being.

\section{DISCUSSION}

In this study, we examined the moderating effects of gender in the association between BMI and psychological wellbeing. Friedman and Brownell (1995) have emphasized the need for an increase in the number and methodological rigor of studies linking BMI to psychological well-being. By using a nationally representative probability-based sample of adults who participated in MIDUS I (Brim et al., 2003), our study takes an important step in providing new and persuasive evidence that women and men vary on psychological well-being as a function of BMI. Our results confirmed our hypothesis; we found that higher BMI was associated with poorer psychological well-being among women but not among men. Furthermore, although of modest size, this moderation effect remained statistically significant even after we added perceived weight and sociodemographic characteristics to the analyses. Mean comparisons of psychological well-being for women and men in five BMI-based groups indicated small but significant gender differences. We found that women in the overweight and obese I groups had significantly lower psychological well-being than men. Moreover, women who were overweight and those in the obese I, II, or III groups had lower psychological wellbeing than their normal-weight counterparts; women in the obese III group also had lower psychological well-being than overweight women. Men, in contrast, did not differ on psychological well-being as a function of BMI-group membership.

Past research has found poor psychological health among obese adults (e.g., Friedman et al., 2002; Friedman et al., 2005) as well as a higher lifetime prevalence of mood and anxiety disorders (Simon et al., 2006). Our results suggest that, for women but not for men, higher body weight may have more pervasive and adverse implications for general psychological health. These findings are consistent with past research that has found greater anxiety reported by women than by men about becoming overweight (Cash \& Brown, 1989; Muth \& Cash, 1997). Because we retested our hypotheses by adding sociodemographic variables to the model, we can be more confident that the gender difference in the link between BMI and psychological wellbeing is valid. More interestingly, however, we found that the moderating role of gender in the BMI-psychological well-being link persisted even after we added participants' perceptions of body weight (i.e., viewing oneself to be very underweight, of the right weight, or very overweight) to the model. Thus, we can conclude that gender differences in the link between BMI and psychological well-being are not 
simply explained by differences in perceptions of weight but instead may be explained by other factors.

One possible explanation for our obtained gender differences may emerge from stigma theory applications to overweight and obese individuals (e.g., Allon, 1981; Carr \& Friedman, 2005; Faulkner et al., 1999; Friedman et al., 2005; Puhl \& Brownell, 2001; Sarlio-Lahteenkorva et al., 1995). Past research indicates that the nature and intensity of the stigma experienced by overweight and obese individuals varies by gender and that women experience stronger social stigma for being overweight relative to their male counterparts (e.g., Chen \& Brown, 2005; Cossrow et al., 2001; Faulkner et al., 1999; Neumark-Sztainer et al., 2002). Indeed, Carr and Friedman (2005) found that gender differences in self-acceptance among overweight and obese women disappeared after controlling for global assessments of discrimination experienced by participants. It is important to note, however, that not all studies have found gender differences in the stigmatizing experience of excessive weight (e.g., Hebl \& Turchin, 2005; Jasper \& Klassen, 1990; Puhl \& Brownell, 2006). For example, Hebl and Turchin (2005) found that men stigmatize obesity in both women and men, and Puhl and Brownell (2006) found no gender differences in the frequency of weight-based stigmatization. Thus, we recommend that future research focus on better understanding differences in the frequency and type of stigmatizing social interactions and experiences of women and men who are overweight or obese. Such differences, in turn, may provide explanations for gender differences in overweight and obese individuals' psychological well-being.

The potential role of stigma in understanding the stronger link between excessive weight and poorer psychological well-being for women than men may be due to prevailing gender-differentiated cultural norms promoting excessive thinness, elusive body size and shape ideals, and the resultant body objectification among women (Fredrickson \& Roberts, 1997). Past research has shown that thinness (as linked to femininity) is closely related to perceived physical attractiveness, especially in Westernized cultures (Cash \& Henry, 1995). Women are likely to internalize cultural norms linking thinness to physical attractiveness and thus view themselves more critically than do men (Fredrickson \& Roberts, 1997; McKinley \& Hyde, 1996). Indeed, Rodin and colleagues (Rodin, Silberstein, \& Striegel-Moore, 1985) observed that body weight dissatisfaction among women in Westernized cultures has become a "normative discontent." This may explain why we found that women with higher-than-normal BMI (ranging from overweight to seriously obese women) have poorer psychological well-being than their normal-weight counterparts. In contrast, among men, greater body weight is linked to greater power and strength inasmuch as the ideal masculine body type is a muscular one (Grogan \& Richards, 2002). This, in turn, may explain why we found that men showed poorer psychological well-being levels that converge with those of women only in the more seriously obese groups. We recommend that future research focus specifically on obese and seriously obese adults in studying the interrelationships among body image, excessive body weight, and psychological outcomes. Although we controlled for the role of perceived weight, this single-item measure, which estimated the extent to which one viewed oneself as underweight or overweight, is at best a proxy measure for the more complex sociocultural constructs of body image and body objectification (Fredrickson \& Roberts, 1997; McKinley \& Hyde, 1996).

Our study indicates that gender reliably moderates the relationship between body weight and psychological wellbeing. It is important to note, however, that the effect sizes we obtained for the moderating role of gender in the body weight-psychological well-being link is small. Likewise, the effect sizes for gender differences in psychological wellbeing within individual BMI groups were modest in magnitude. Our large sample size enabled us to detect these small effect sizes, and it is important to weigh the practical significance of our results in conjunction with their statistical significance. Moreover, our study is based on cross-sectional data, and thus we cannot draw conclusions about the direction of causal relationships linking BMI and psychological well-being. Nevertheless, regardless of whether excessive body weight leads to poorer psychological well-being or the reverse, our results provide evidence that women and men vary in the strength of the association between these variables, with the association being stronger for women than for men.

Another limitation of our study is that in MIDUS I (Brim et al., 2003), BMI computation was based on selfreports of weight and height obtained from the participants rather than on objective evaluations. It is possible, therefore, that respondents did not accurately report their vital statistics. However, at least in the case of self-reports of weight, heavier individuals may be likely to underreport rather than overreport their weight. For example, a study by Koslowski, Scheinberg, Bleich, and Mark (1994) found that participants who weighed more tended to underreport their weight. In light of this tendency for heavier individuals to underreport their weight, it is likely that we would find even stronger moderating effects of gender in the relationship between body weight and psychological well-being if BMI had been measured directly. Nevertheless, we urge future studies to use objective assessments of vital statistics when measuring body weight.

Third, as pointed out above, MIDUS I did not include a well-established measure of body image. As a result, we were not able to explore more fully the role of gender differences in body image as a potential moderator or mediator of the link between BMI and psychological well-being. The single-item measure of perceived weight, however, did permit us to account at least partially for psychological representations of body weight in the regression model. Finally, although we included age, education, ethnicity, marital status, and perceived weight as covariates in our analyses, this 
list may not include all relevant variables. Future research may benefit by including other covariates of BMI and/or psychological well-being, such as employment status, U.S. region, and physical health.

In closing, we would like to highlight that our study is marked by several strengths that enhance our confidence in its findings. We used data from a large, nationally representative probability-based, nonclinical sample of adults; we examined the moderating role of gender in the association between body weight and psychological well-being after controlling for sociodemographic variables; and we controlled for the role of perceived weight. In doing so, we make original contributions to the intersecting literatures on gender differences, body weight, and psychological health.

Initial submission: June 27, 2007

Initial acceptance: September 14, 2007

Final acceptance: October 22, 2007

\section{NOTE}

1. Individuals with BMI below that defined as "normal" (i.e., BMI $<18.5 ; n=77$ ) were excluded from the analyses. It should be noted that women outnumbered men in this category $(n=62$ vs. 15$)$; the two groups did not differ significantly on psychological well-being $(M=99.6$ and 96.6 for women and men, respectively; $t(75)=-.83, p=.407 ; \eta^{2}=.011$ )

\section{REFERENCES}

Adams, K. F., Schatzkin, A., Harris, T. B., Kipnis, V., Mouw, T., Ballard-Babash, R., et al. (2006). Overweight, obesity, and mortality in a large prospective cohort of persons 50 to 71 years old. New England Journal of Medicine, 355, 763778 .

Aiken, L. S., \& West, S. G. (1991). Multiple regression: Testing and interpreting interactions. Thousand Oaks, CA: Sage.

Allon, N. (1981). The stigma of overweight in everyday life. In B. Wolman (Ed.), Psychological aspects of obesity: A handbook (pp. 130-174). New York: Van Nostrand Rheinhold.

Brim, O. G., Baltes, P. B., Bumpass, L. L., Cleary, P. D., Featherman, D. L., Hazzard, W. R., et al. (2003). National Survey of Midlife Development in the United States, 19951996 (Second ICPSR version) [Data file]. Ann Arbor, MI: DataStat Inc./Boston: Harvard Medical School, Department of Health Care Policy [producers]/Ann Arbor, MI: Inter-University Consortium for Political and Social Research [distributor].

Brodie, D. A., \& Slade, P. D. (1988). The relationship between body image and body-fat in adult women. Psychological Medicine, 18, 623-631.

Carr, D. S., \& Friedman, M. A. (2005). Is obesity stigmatizing? Body weight, perceived discrimination, and psychological well-being in the United States. Journal of Health and Social Behavior, 46, 244-259.

Carr, D. S., \& Friedman, M. A. (2006). Bodyweight and the quality of interpersonal relationships. Social Psychology Quarterly, 69, 127-149.
Carr, D. S., Friedman, M. A., \& Jaffe, K. (2007). Understanding the relationship between obesity and positive and negative affect: The role of psychosocial mechanisms. Body Image, $4,165-177$.

Cash, T. F., \& Brown, T. A. (1989). Gender and body image: Stereotypes and realities. Sex Roles, 21, 361-373.

Cash, T. F., \& Henry, P. E. (1995). Women's body images: The result of a national survey in the U.S.A. Sex Roles, 33, 1928.

Chen, E. Y., \& Brown, M. (2005). Obesity stigma in sexual relationships. Obesity Research, 13, 1393-1397.

Cossrow, N. H. F., Jeffery, R. W., \& McGuire, M. W. (2001). Understanding weight stigmatization: A focus group study. Journal of Nutrition Education, 33, 208-214.

Crandall, C. S. (1994). Prejudice against fat people: Ideology and self-interest. Journal of Personality and Social Psychology, 66, 882-894.

Crandall, C. S., \& Schiffhauer, K. L. (1998). Anti-fat prejudice: Beliefs, values, and American culture. Obesity Research, 6 , 458-460.

Crocker, J., Cornwell, B., \& Major, B. (1993). The stigma of overweight: Affective consequences of attributional ambiguity. Journal of Personality and Social Psychology, 64, 60-70.

Davison, T. E., \& McCabe, M. P. (2005). Relationships between men's and women's body image and their psychological, social, and sexual functioning. Sex Roles, 52, 463-475.

Faulkner, N. H., French, S. A., Jeffery, R. W., Neumark-Sztainer, D., Sherwood, N. E., \& Morton, N. (1999). Mistreatment due to weight: Prevalence and sources of perceived mistreatment in women and men. Obesity Research, 7, 572576.

Fredrickson, B. L., \& Roberts, T. A. (1997). Objectification theory: Toward understanding women's lived experiences and mental health risks. Psychology of Women Quarterly, 21, 173-206.

Friedman, K. E., Reichmann, S. K., Costanzo, P. R., \& Musante, G. J. (2002). Body image partially mediates the relationship between obesity and psychological distress. Obesity Research, 10, 33-41.

Friedman, K. E., Reichmann, S. K., Costanzo, P. R., Zelli, A., Ashmore, J. A., \& Musante, J. G. (2005). Weight stigmatization and ideological beliefs: Relation to psychological functioning in obese adults. Obesity Research, 13, 907-916.

Friedman, M. A., \& Brownell, K. D. (1995). Psychological correlates of obesity: Moving to the next research generation. Psychological Bulletin, 177, 3-20.

Grogan, S., \& Richards, H. (2002). Body image: Focus groups with boys and men. Men and Masculinities, 4, 219-232.

Harris, M. B., Harris, R. J., \& Bochner, S. (1982). Fat, four-eyed, and female: Stereotypes of obesity, glasses, and gender. Journal of Applied Social Psychology, 12, 503-516.

Hebl, M. R., \& Turchin, J. M. (2005). The stigma of obesity: What about men? Basic and Applied Social Psychology, 3, 267275.

Heo, M., Pietrobelli, A., Fontaine, K. R., Sirey, J. A., \& Faith, M. S. (2006). Depressive mood and obesity in US adults: Comparison and moderation by age, sex, and race. International Journal of Obesity, 30, 513-519.

Jasper, C. R., \& Klassen, M. L. (1990). Perceptions of salespersons' appearance and evaluation of job performance. Perceptual and Motor Skills, 71, 563-566. 
Koslowski, M., Scheinberg, Z., Bleich, A., \& Mark, M. (1994). Predicting actual weight from self-report data. Educational and Psychological Measurement, 54, 168-173.

Latner, J. D., Stunkard, A. J., \& Wilson, G. T. (2005). Stigmatized students: Age, sex, and ethnicity effects in the stigmatization of obesity. Obesity Research, 13, 1226-1231.

McKinley, N. M., \& Hyde, J. S. (1996). The objectified body consciousness scale: Development and validation. Psychology of Women Quarterly, 20, 181-215.

Mustajoki, P. (1987). Psychosocial factors in obesity. Annals of Clinical Research, 19, 143-146.

Muth, J. L., \& Cash, T. F. (1997). Body-image attitudes:What difference does gender make? Journal of Applied Social Psychology, 27, 1438-1452.

National Center for Health Statistics. (2006). Health, United States, 2006: With chartbook on trends in the health of Americans. Hyattsville, MD: Author.

National Heart, Lung, and Blood Institute. (1998). Clinical guidelines on the identification, evaluation, and treatment of overweight and obesity in adults: The evidence report (Publication 98-4803). Bethesda, MD: National Institutes of Health.

Neumark-Sztainer, D., Falkner, N., Story, M., Perry, C., Hannan, P. J., \& Mulert, S. (2002). Weight-teasing among adolescents: Correlations with weight status and disordered eating behaviors. International Journal of Obesity, 26, 123131.

Ogden, C. L., Carroll, M. D., Curtin, L. R., McDowell, M. A., Tabak, C. J., \& Flegal, K. M. (2006). Prevalence of overweight and obesity in the United States, 1999-2004. Journal of the American Medical Association, 295, 15491555.

O’Neil, P. M., \& Jarrell, M. P. (1992). Psychological aspects of obesity and dieting. In T. A. Wadden \& T. B. Van Itallie (Eds.), Treatment of the seriously obese patient (pp. 252270). New York: Guilford.

Puhl, R., \& Brownell, K. D. (2001). Bias, discrimination, and obesity. Obesity Research, 9, 788-805.

Puhl, R., \& Brownell, K. D. (2006). Confronting and coping with weight stigma: An investigation of overweight and obese individuals. Obesity, 14, 1802-1815.

Rodin, J., Silberstein, L. R., \& Striegel-Moore, R. H. (1985). Women and weight: A normative discontent. Nebraska Symposium on Motivation, 32, 267-307.
Ryff, C. D. (1989). Happiness is everything, or is it? Explorations on the meaning of psychological well-being. Journal of Personality and Social Psychology, 57, 1069-1081.

Sarlio-Lahteenkorva, S., Stunkard, A., \& Rissanen, A. (1995). Psychosocial factors and quality of life in obesity. International Journal of Obesity, 6, S1-S5.

Sarwer, D. B., Wadden, T. A., \& Foster, G. D. (1998). Assessment of body image dissatisfaction in obese women: Specificity, severity, and clinical significance. Journal of Consulting and Clinical Psychology, 66, 651-654.

Simon, G. E., Von Korff, M., Saunders, K., Miglioretti, D. L., Crane, P. K., Van Belle, G., et al. (2006). Association between obesity and psychiatric disorders in the US adult population. Archives of General Psychiatry, 63, 824-830.

Sinclair, S. L., \& Myers, J. E. (2004). The relationship between objectified body consciousness and wellness in a group of college women. Journal of College Counseling, 7, 59-161.

Springer, K. W., Hauser, R. M., \& Freese, J. (2006). Bad news indeed for Ryff's six-factor model of well-being. Social Science Research, 35, 1120-1131.

Stunkard, A. J., \& Mendelson, M. (1967). Disturbances in body image of some obese persons. Journal of the American Dietetic Association, 38, 328-331.

Tiggemann, M., \& Rothblum, E. D. (1998). Gender differences in social consequences of perceived overweight in the United States and Australia. Sex Roles, 18, 75-86.

Wadden, T. A., \& Stunkard, A. J. (1993). Psychosocial consequences of obesity and dieting-Research and clinical findings. In A. J. Stunkard \& T. A. Wadden (Eds.), Obesity theory and therapy (pp. 163-177). New York: Raven Press.

Wang, P. W., Sachs, G. S., Zarate, C. A., Marangell, L. B., Calabrese, J. R., Goldberg, J. F., et al. (2006). Overweight and obesity in bipolar disorders. Journal of Psychiatric Research, 40, 762-764.

Weaver, A. D., \& Byers, E. S. (2006). The relationships among body image, body mass index, exercise, and sexual functioning in heterosexual women. Psychology of Women Quarterly, 30, 333-339.

Weiner, B., Perry, R. P., \& Magnusson, J. (1988). An attributional analysis of reactions to stigmas. Journal of Personality and Social Psychology, 55, 738-748.

World Health Organization. (2002). The World Health Report 2002: Reducing risks, promoting healthy life. Geneva, Switzerland: World Health Organization. 